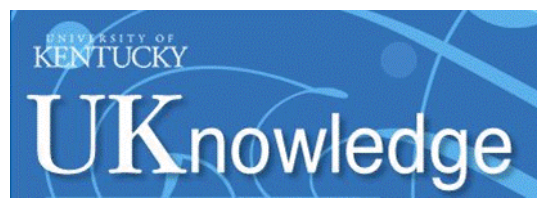

University of Kentucky

UKnowledge

10-2017

\title{
Statin Use and Venous Thromboembolism in Cancer: A Large, Active Comparator, Propensity Score Matched Cohort Study
}

\author{
Sherif M. El-Refai \\ University of Kentucky, smelrefai@uky.edu \\ Esther P. Black \\ University of Kentucky, penni.black@uky.edu \\ Val R. Adams \\ University of Kentucky, val.adams@uky.edu \\ Jeffery C. Talbert \\ University of Kentucky, jeff.talbert@uky.edu
}

See next page for additional authors

Right click to open a feedback form in a new tab to let us know how this document benefits you. Follow this and additional works at: https://uknowledge.uky.edu/ps_facpub 
Statin Use and Venous Thromboembolism in Cancer: A Large, Active Comparator, Propensity Score Matched Cohort Study

Digital Object Identifier (DOI)

https://doi.org/10.1016/j.thromres.2017.08.001

Notes/Citation Information

Published in Thrombosis Research, v. 158, p. 49-58.

(c) 2017 Elsevier Ltd. All rights reserved.

This manuscript version is made available under the CC-BY-NC-ND 4.0 license

https://creativecommons.org/licenses/by-nc-nd/4.0/.

The document available for download is the author's post-peer-review final draft of the article.

Authors

Sherif M. El-Refai, Esther P. Black, Val R. Adams, Jeffery C. Talbert, and Joshua D. Brown 


\title{
Statin use and venous thromboembolism in cancer: A large, active comparator, propensity score matched cohort study
}

\author{
Sherif M. El-Refai ${ }^{\mathrm{a}}$, Esther P. Black ${ }^{\mathrm{a}}$, Val R. Adams ${ }^{\mathrm{b}}$, Jeffery C. Talbert ${ }^{\mathrm{b}}$, and Joshua D. \\ Brown $^{b, c, *}$ \\ aDepartment of Pharmaceutical Sciences, University of Kentucky College of Pharmacy, \\ Lexington, KY, USA \\ bepartment of Pharmacy Practice and Science, University of Kentucky College of Pharmacy, \\ Lexington, KY, USA \\ 'Department of Pharmaceutical Outcomes and Policy, University of Florida College of Pharmacy, \\ Gainesville, FL, USA
}

\begin{abstract}
Background-Statins have been shown to have a protective effect for venous thromboembolism (VTE) in the general population. This study sought to assess the association between statins and the risk for cancer-associated deep vein thrombosis (DVT) and pulmonary embolism (PE).

Methods-Patients with newly diagnosed cancer were followed for up to one year in a healthcare claims database (2010-2013). Three treatment groups included statin users, non-statin cholesterol lowering medication users, and an untreated group with pre-existing indications for statin therapy (hyperlipidemia, diabetes, or heart disease). Propensity score matched groups were compared using competing risks survival models for DVT and PE outcomes reporting the hazard ratios (HR) between the treatment groups. Sensitivity analyses assessed the influence of age and individual medications.
\end{abstract}

Results-The total cohort included 170,459 patients, which, after matching, were similar on baseline characteristics. The overall model showed a statistically significant protective effect for statins compared to no treatment attributed only to leukemia for DVT (HR $=0.77,95 \%$ CI $0.61-$ $0.99)$ and colorectal cancers for PE ( $\mathrm{HR}=0.80,95 \% \mathrm{CI} 0.64-0.99)$ in stratified analyses. There were generally no differences in outcomes between statins and non-statins and no individual statin use showed results different from the class effect.

Conclusions-In this propensity score matched sample of patients with cancer, statins were shown to have a small protective effect in some cancers for DVT or PE compared to no treatment and little difference compared to an active control group. The lack of effect was consistent across statins and was also not found for any of the sensitivity analyses included.

*Corresponding author at: 1225 Center Drive, HPNP Building, \#3320, PO Box 100496, Gainesville, FL 32610-0496, USA. joshua.brown@ufl.edu (J.D. Brown).

Disclosures

There are no relevant disclosures or conflicts of interest. 


\section{Keywords}

Statins; Venous thromboembolism; Cancer; Deep vein thrombosis; Pulmonary embolism

\section{Introduction}

Cancer is among the most established independent risk factors for venous thromboembolism (VTE) [1]. Compared to the general population, individuals with cancer are at 4 to 7 times the risk of developing a VTE [2-5]. Malignancy induces a pro-thrombotic state, which includes activation of the coagulation cascade and is further exacerbated by cancer treatment [6]. Additional risk factors for VTE in cancer include patient specific factors such as the site and stage of the tumor, older age, prior history of thrombosis, and other comorbidities [7,8]. Although at an already increased risk of death from cancer, VTE carries a substantial risk of mortality with clotting events accounting for up to $10 \%$ of all deaths in patients with cancer [9-11].

Several studies have shown a link between statins and reduced risk of VTE [12-23]. Although the class is generally indicated to reduce atherosclerotic cardiovascular disease, inflammation underlies the pathogenesis of both disorders, and the anti-inflammatory effects of statins have been documented [14]. A key component of this process is the inhibition of isoprenoid synthesis, which impairs prenylation events. Although the anti-inflammatory properties seem to be independent from the lipid lowing properties, the effects differ among tissues [24]. It has further been shown that statins have antithrombotic properties and influence the vascular system in other ways [25]. The Heart and Estrogen/Progestin Replacement Study (HERS) and the JUPITER trial showed roughly a 50\% decrease in the risk of VTE in the general population $[17,26]$. This finding has been substantiated in metaanalyses, but shows a small risk reduction (10-20\%) in the largest of these studies [15]. Tagalakis and colleagues evaluated statin use and recurrent VTE risk in a cohort $\ 65$ years of age with cancer and found a reduction in VTE risk associated with current statin use with further reduction with longer duration of treatment [27]. Similarly, a case-control study conducted in patients with cancer found the risk of cancer-associated VTE was $8 \%$ in those treated with statins compared to $21 \%$ in those without statin treatment [20].

The potential role and interest for statins as prophylaxis against cancer-associated VTE lies in the general safety of the class as well as other benefits associated with the class (e.g. decreased cardiovascular events). Statins pose no risk of bleeding; thus, if effective, they could hypothetically be used in patients who are contraindicated to anticoagulation, for longterm prophylaxis where indefinite anticoagulation is not preferred, or as adjunct therapy in those already anticoagulated. However, the literature has generally shown a small overall benefit or has been limited by small patient populations with few outcome events to compare. Robust comparisons with an active control and detailed sensitivity analyses are also needed to strengthen the findings observed in past studies.

This study investigated the association between statin use and cancer-associated VTE in a U.S.-based cohort. We compared statin users with users of other non-statin cholesterol lowering medications as well as an untreated group, using propensity score matching 
techniques to reduce selection bias and confounding. Sensitivity analyses included investigation whether certain statins provide different effects and for age as an effect modifier.

\section{Methods}

This retrospective cohort study used the Truven Health MarketScan Commercial Claims and Medicare Supplemental Databases from the years 2010-2013. The MarketScan data include approximately 40 million individuals from over 160 large employers and health plans across the U.S. The data represent an individual's healthcare utilization including medical claims with diagnosis and procedure codes for medical encounters and all prescription medication fills. These data are de-identified in compliance with the Health Insurance Portability and Accountability Act regulations (HIPAA) and the University of Kentucky Institutional Review Board approved the use of the database for this study.

\subsection{Cohort selection}

Adults aged 18 years and older diagnosed with cancer between January 1, 2010 and November 31, 2013 were identified. The date of the first qualifying diagnosis of cancer was defined as the index date. Patients selected were diagnosed with one of the following types of cancer: Stomach, Pancreatic, Brain, Lung, Renal, Lymphoma, Leukemia, Myeloma, Colorectal, or Gynecological; identified using International Classification of Disease, 9th revision (ICD-9) codes. At least 2 inpatient or outpatient diagnoses separated by at least 14 days were required to confirm the cancer diagnosis. Patients were further required to have at least 12 months of pre-index and a 1-month minimum of post-index continuous enrollment with medical and pharmacy information included in the database.

\subsection{Treatment groups}

Treatment groups were defined as: statin users with no history of non-statin medication use; non-statin cholesterol-lowering medication users with no history of statin use ("non-statin users," active control group); and those with no history of statin or non-statin medication use ("no treatment," control group). History of medication use was based on the 12 months of pre-index look back period. Current medication use for treatment group assignment was based on having at least 90 cumulative days supplied of the medications in the 6 months prior to diagnosis to establish some minimum of exposure to each medication class. Statins included were lovastatin, pravastatin, simvastatin, rosuvastatin, atorvastatin, fluvastatin and pitavastatin. Non-statins include cholesterol absorption inhibitors, fibric acid derivatives, bile acid sequestrants, and nicotinic acid. The no treatment group was restricted to individuals with a pre-index history of hyperlipidemia, coronary heart disease, or diabetes to identify a more comparable no treatment group with indications for statin therapy.

\subsection{Study covariates}

Patient demographic characteristics included age, gender, geographic region and urban residence. Clinical characteristics measured during the 12-month pre-index period included the Charlson Comorbidity Index (CCI) as a measure of comorbidity burden. Individual comorbidities were also included as binary variables indicating any prior diagnosis for these 
conditions based on a list of Elixhauser comorbidities. These comorbidity indices include 17 and 31 categories of comorbid conditions, respectively, and are widely used for risk adjustment with health outcomes data [28-30]. Additional pre-index medications accounted for included anticoagulants, antihypertensives, antiplatelets, antiarrhythmics, and digoxin, operationalized as binary exposures during the pre-index period.

\subsection{Outcome measures}

VTE outcomes included deep vein thrombosis (DVT) and pulmonary embolism (PE). Two separate ICD-9 coding sets were used for each outcome accounting for a broad approach and a more stringent definition. The broader approach included ICD-9 codes 451.xx and 453.xx for DVT and 415.1x for PE. The more strict definition was based on a validated ICD-9 code set, which includes a subgroup of these codes [31,32]. Results from the more strict definition of VTE events are discussed in the text while results from both definitions are provided in the Appendices.

\subsection{Propensity score matching}

Pairwise analyses were conducted between two treatment groups at a time: statins vs. nonstatins, statins vs. non-users, and non-statins vs. non-users. Propensity score matching mimics the randomization process of a clinical trial so that each matched pair has the same baseline probability to receive either treatment [33]. Propensity score matching was conducted using treatment probabilities derived from baseline comorbidities, medications, and demographic information to achieve balance between treatment groups. A multivariable logistic regression model was used to predict the propensity of receiving one treatment versus the other for each pair and included all baseline characteristics (Table 1). Patients were matched on this propensity score with another patient with the same type of cancer in the comparison treatment group using a greedy algorithm ("gmatch" SAS macro) allowing for up to 4 matches. Matches were required to have a propensity score within $20 \%$ of the standard deviation of the cohort's mean propensity score. Once matched, pairs are theoretically similar, conditional on the included covariates in the logistic regression model generating the propensity score estimates [34]. Standardized differences were calculated to assess the balance achieved between the treatment groups by the matching process [35]. Standardized differences of $<0.10$ are generally considered to be non-significant. Covariates with standardized differences above this threshold were also incorporated in the final regression models to reduce any residual selection bias. Comparison of the pre-matched sample (Appendix Table 1) using standard $p$-values was not done due to the use of the matched sample for study results. Incidence rates were calculated based on cumulative follow-up per 1000 person-years and the number needed to treat (NNT) was calculated based on the differences between incidence rates for the comparison groups.

\subsection{Survival analysis}

The study cohort was followed until subjects died, were lost to follow-up, or the end of the study data (December 31, 2013). Since the competing risk of death was present in the cohort and would prevent the occurrence of the outcomes of interest, two survival regression models were estimated - a cause-specific hazard model and a sub-distribution hazard model [36]. These models differ in how patients who die during follow-up are included in the risk 
set. In the cause-specific model, death is treated as a censoring event; thus, it reduces to a traditional Cox proportional hazard model. The resulting cause-specific hazard ratio (csHR) represents the instantaneous rate of VTE among subjects who are event free (no VTE, no death) [36]. The sub-distribution model retains those who die in the risk set at each time interval and the sub-distribution HRs represent the instantaneous rate of VTE in those who have not experienced VTE or who have died. Including both models allowed for a more broad interpretation of results as each has unique implications and applications [36]. This manuscript primarily reports results from the cause-specific models as they are more traditionally interpreted similarly to Cox proportional hazard models. Results from the subdistribution models are presented in Appendix Table 2 for the primary analyses only. Models for separate DVT and PE outcomes were estimated overall as well as stratified by each cancer type. Time-varying treatment models were considered, however, it was observed that the overall statin and non-statin utilization was $\geqq 90 \%$ during follow-up, making a timevarying treatment model unlikely to influence results. The cumulative incidence of a composite DVT/PE outcome was also estimated accounting for death as a competing risk using the Fine and Gray method. The assumption of proportional hazards was checked and confirmed using Schoenfeld residuals. Hazard ratios and cumulative incidence estimates are presented with $95 \%$ confidence intervals in parentheses. Data management and statistical analyses were conducted using SAS Enterprise Guide version 7.1 (Cary, NC).

\subsection{Sensitivity analyses}

A sensitivity analysis assessing the influence of age as an effect modifier stratified the overall survival models by ages $564,65-74$, and 75 and older as these patients may have different treatments patterns, response, and varying baseline survival. Statins were also internally compared as individual chemical entities and by type (natural vs. synthetic) to ascertain if differences among statins influence outcomes. Natural statins include lovastatin, pravastatin and simvastatin and synthetic statins included rosuvastatin, atorvastatin, fluvastatin and pitavastatin. Influence of a statin dose-response relationship was also explored but did not differ from the primary analyses.

\section{Results}

During the 5-year study period, 170,459 patients with cancer met the eligibility criteria with lung, lymphomas, and colorectal cancers being the most commonly diagnosed cancers. The three treatment groups included statins $(N=61,057)$, non-statins $(N=10,268)$, and no treatment $(N=99,134)$. At baseline, these three groups differed by age and comorbid conditions; however, propensity score matching provided matched pairs that were similar based on standardized differences (Table 1). Each treatment group contributed an average of 290 days of follow-up per patient with non-significant differences ( \pm 5 days) in follow-up time.

\subsection{Statins vs. no treatment}

After propensity score matching, 39,821 statin users matched 1:1 with the no treatment group. The incidence rate (Table 2) between the statin and no treatment groups was 72.7 versus 80.1 DVTs $(\mathrm{NNT}=146, P<0.001)$ and 33.4 versus $35.6 \mathrm{PEs}(\mathrm{NNT}=471, P>0.05)$ 
per 1000 person-years. The one-year cumulative incidence of DVT/PE combined was $8.1 \%$ $(7.9 \%-8.4 \%)$ and $8.3 \%(8.2 \%-8.5 \%)$ in the statin and untreated groups. In the cause-specific survival model (Table 3), statin treatment was associated with a small reduction in DVT [csHR $0.92(0.87-0.97)]$. In analyses stratified by cancer type, leukemia and colorectal cancers accounted for the only significant results. For leukemia, there was a reduction in DVT only [csHR 0.77 (0.61-0.99)]. Point estimates for PE outcomes in the leukemia were all $<1.0$, but included wide confidence intervals, which included the null. In colorectal cancer, the risk of PE [csHR 0.80 (0.64-0.99)] was significantly reduced. Results from the sub-distribution hazard models were similar in direction and magnitude for these and all further results (Appendix Table 2). Similarly, results using the more broad definition of VTE provided nearly identical results to the more strict event coding (Appendix Table 3).

\subsection{Statins vs. non-statins}

In the comparison between statin and non-statin cholesterol-lowering medications, the overall model showed no significant results in a matched sample of 51,983 statin users and 15,334 non-statin users. The incidence rate in each group was 72 versus 71.2 DVTs (NNT > $1000)$ and 33.3 versus 34.5 PEs $(\mathrm{NNT}=862)$ per 1000 person-years (both $P>0.05)$, respectively. The cumulative incidence of DVT/PE at 1-year of follow-up was $8.2 \%$ (7.9\%$8.5 \%)$ for the statin group and $8.5 \%(7.9 \%-9.1 \%)$ in the non-statin group. When stratified by cancer type, only lung cancer showed a protective effective of statins for PE [csHR 0.79 (0.64-0.99)] but not for DVT.

\subsection{Non-statins vs. no treatment}

There was significant differences in DVT incidence between non-statin $(N=10,621)$ and no treatment $(N=37,098)$ groups $(71.5$ vs. $79, \mathrm{NNT}=144, P<0.001)$ in the observed incidence of DVT but not PE (34.6 vs. 35.2, NNT > 1000, $P>0.05$ ). The cumulative incidence of any VTE at 1-year was comparable at $8.5 \%(7.9 \%-9.1 \%)$ in the non-statin group and $8.5 \%(8.1 \%-8.8 \%)$ in the untreated group. In all models comparing the non-statin and untreated groups, there were no significant findings for either outcome.

\subsection{Statin sensitivity analysis}

Among the statin treated group, 37,318 (61.1\%) received natural statins including simvastatin $(N=26,818 ; 71.9 \%$ of natural statin users) pravastatin $(N=6824 ; 18.3 \%)$, and lovastatin $(N=3676 ; 9.9 \%)$. Synthetic statins were used by 23,739 (38.9\%) of patients and included atorvastatin $(N=17,224 ; 72.6 \%$ of synthetic statin users), rosuvastatin ( $N=6063$; $25.5 \%)$, fluvastatin $(N=347 ; 1.5 \%)$, and pitavastatin $(N=105,0.4 \%)$. When comparing natural versus synthetic statins, there was no difference in outcomes (Table 4). A more indepth analysis using simvastatin as the reference group, found no significant differences observed between any of the individual statins versus simvastatin in DVT or PE outcomes (Table 4). 


\subsection{Age stratification sensitivity analysis}

When the overall model was stratified by age groups, the protective effect on DVT observed for statins and non-statin treated patients compared to untreated patients was present only for those 75 and older (Table 5).

\section{Discussion}

Statins have been an attractive target in the literature for prevention of VTE given the general safety of the class, effectiveness in reducing cardiovascular disease, and broader pleiotropic, and potential anti-cancer activity. In the cancer population, having new options for adjunct treatment for primary or secondary prevention of VTE is desirable given the considerable burden of VTE associated with cancer, high risk of recurrence, and difficulty in managing anticoagulation in these patients [38].

The current study utilized pharmacoepidemiological techniques to compare the treatment effect of statins on the rate of DVT and PE in a cancer cohort compared to non-statin, cholesterol-lowering medications and an untreated group. Compared to the no treatment group, statins had a small protective effect (10-15\%) in VTE associated with colorectal cancer and leukemias. These results did not hold true for other cancer types or for in comparisons of statins to non-statin medications. The estimated number needed to treat (NNT) compared for statins compared to no treatments is >100 and may not meet an acceptable threshold to initiate new pharmacotherapy for newly diagnoses cancers to prevent VTE. Further, there were no protective results shown with statins for PE in any of the models other than for the comparison of statins versus non-statins for lung cancer (HR = $0.79,95 \%$ CI 0.64-0.99). Stratification by age showed that these results were only consistent in patients $\geq 75$ years old - a finding that deserves further investigation. Therefore, there seems to not be an overall protective benefit from using statins when compared either to non-statin cholesterol-lowering drugs or no treatment. It is unknown whether there may be a pathway by which statins may show a differential protective effect only for DVTs and only in colorectal cancer and leukemias. The few protective findings we did observe may have been spurious or need further study to identify physiological or pharmacological pathways to explain these effects.

These results differ from those observed in other clinical trials and observational studies in the general population without concurrent cancer. The JUPITER trial, which randomized patients with low-density lipoprotein cholesterol levels $<130 \mathrm{mg} / \mathrm{dL}$ and C-reactive protein levels $\geq 2.0 \mathrm{mg} / \mathrm{L}$ to receive rosuvastatin or placebo, found a $40-50 \%$ reduction in the rate of VTE [17]. The strict selection criteria of the JUPITER trial may confound the comparison and generalizability of those findings to the general population. Similarly, a study by Lassila and colleagues found a reduction in VTE of $40 \%$ but with a wide confidence interval that approached the null [18]. Meta-analyses have also shown a smaller (10-20\%) marginal effect of statins in the general population, which is more consistent to the findings in our study focusing on a cancer population [15,19].

Two known studies have specifically investigated statin use and VTE risk in cancer. Lötsch et al. used propensity score weighting techniques to compare statin users with non-users in 
newly diagnosed cancer or cancer in remission [23]. They observed a protective effect of statins using a sub-distribution hazard model ( $\mathrm{sdHR}=0.43,95 \%$ CI 0.19-0.98) and investigated the effect of multiple biomarkers for VTE risk. However, this study was limited by a relatively small sample $(N=1434)$ and, in particular, with only 6 VTE events in the statin group [23]. Further, comparison to a no treatment group can be troublesome given lack of indication for the therapy of interest - in this case statins, and no assessment of how the no treatment group compared to the statin user group was included in that study. In addition to statin users and non-users being confounded by indication, healthy user bias is also possible between statin users and no treatment groups wherein individuals who should be on statins are not due to non-compliance to treatment or due to other factors. To address this, our study used both an active comparator with similar therapeutic indications (non-statin cholesterol-lowering medications) in addition to restricting the no treatment comparator to those with statin indications. Including an active comparator helps to control for this effect and provides a more comparable group to the statin users. Another study used a case-control study design of 740 patients at a single medical center. Their results suggested a protective association with statin use, however, they were similarly limited in the number of events ( $N$ $=16$ ) in the statin user group as well as the general limitations of case-control studies [20].

Despite the lack of a large observed effect in this study, statins have potential for other repurposed use in cancer. A recent study compared the use of aspirin, statins, selective serotonin reuptake inhibitors, adrenergic receptor alpha 1 antagonist, and tricyclic antidepressants in small cell lung cancer identified a statistically significant increase in median overall survival associated with statin treatment ( 8.4 vs. 6 months, respectively; $P=$ 0.002) [39]. This effect may be due to statins' influence on the mevalonate pathway, of which, HMG $\backslash \mathrm{CoA}$ reductase is the rate-limiting enzyme. In turn, this will lead to decreased production of downstream mevalonate derivatives, farnesyl pyrophosphate (FPP), and geranyl geranyl pyrophosphate (GGPP) [40]. Ras activation requires covalent attachment to FPP or GGPP to be directed to the endoplasmic reticulum for further processing [41]. Ras protein activation leads to transcription of several different genes involved in cell differentiation [42]. Thus, despite our results for VTE, investigation into the effect of statins in cancer should continue in order to elucidate pathways by which statins may exert unintended benefits of their use [19].

\subsection{Limitations}

This study is subject to the limitations of all claims-based studies [43, 44]. Notably, claims data lack detailed information on laboratory values, additional sociodemographic information, smoking status, or information on tumor staging, which may have influenced the outcomes of this study but is not expected to be differential between comparison groups. The population included in the claims database included individuals covered by employer provided, commercial or retiree health insurance and is generalizable to the commercially insured population in the U.S. but may not be generalizable to other populations. This study was limited to a one-year follow-up due to the availability of data and the potential for timevarying confounded and increased heterogeneity with longer follow-up of patients with cancer. Analyses were stratified by cancer type to investigate effects within each cancer but also to control for varying baseline hazards as well as varying treatment trajectories between 
cancers. While treatments including chemotherapy, radiation, surgery, use of thromboprophylaxis, etc. may differ between cancers and are known to be associated with VTE risk, it is not expected to be differential between treatment groups within the same cancer type. Studies with longer follow-up are needed to confirm the sustainability of the protective effect of statins observed in this study and detailed investigation incorporating time-varying cancer treatment characteristics within each cancer may be warranted for those cancers (renal, colorectal, and leukemias) where a protective signal was observed. Lastly, while propensity score matching is known to reduce selection bias in non-randomized studies, it is possible that residual bias is present, especially when there are important unmeasured confounders that are not included in the model [33]. This study is strengthened by a large sample size, a large number of outcome events, inclusion of minimum medication exposure criteria (i.e. 90 days supplied in pre-index period), and by inclusion of an active control group in addition to tight restriction of the no treatment comparator group, which have all been lacking in previous studies.

\section{Conclusion}

In this propensity score matched sample of patients with cancer, statins were shown to have a small protective effect in colorectal cancers and leukemias for the risk of DVT. The lack of effect was consistent across sensitivity analyses included and did not persist in comparisons to non-statin medications. While this study indicates statins may not have a role in preventing cancer-associated VTE, there exist other opportunities for statins to be repurposed in other therapeutic applications.

\section{Acknowledgments}

Sources of funding

The project described was supported by the National Center for Advancing Translational Sciences, National Institutes of Health, through grant number UL1TR000117. The content is solely the responsibility of the authors and does not necessarily represent the official views of the NIH. Drs. Adams and Brown were supported by a grant from the Hematology/Oncology Pharmacists Association.

\section{Appendix A}

\section{Appendix Table 1}

Cohort characteristics prior to propensity score matching.

\begin{tabular}{|c|c|c|c|c|c|c|}
\hline & \multicolumn{6}{|c|}{ Treatment group } \\
\hline & \multicolumn{2}{|c|}{$\begin{array}{l}\text { Statins } \\
N=\mathbf{6 1 , 0 5 7} \\
\end{array}$} & \multicolumn{2}{|c|}{$\begin{array}{l}\text { Non-statins } \\
N=\mathbf{1 0 , 2 6 8} \\
\end{array}$} & \multicolumn{2}{|c|}{$\begin{array}{l}\text { No treatment } \\
N=\mathbf{9 9 , 1 3 4}\end{array}$} \\
\hline & Mean & SD & Mean & SD & Mean & SD \\
\hline Age & 74.8 & 7.9 & 72.3 & 9.1 & 62.9 & 12.1 \\
\hline \multirow[t]{2}{*}{ Charlson comorbidity index } & 5.1 & 3.0 & 5.1 & 3.0 & 4.9 & 3.1 \\
\hline & $\mathrm{N}$ & $\%$ & $\mathrm{~N}$ & $\%$ & $\mathrm{~N}$ & $\%$ \\
\hline Gender (Male) & 32,101 & $52.6 \%$ & 5587 & $54.4 \%$ & 47,030 & $47.4 \%$ \\
\hline Urban residence & 51,917 & $85.0 \%$ & 8584 & $83.6 \%$ & 82,791 & $83.5 \%$ \\
\hline
\end{tabular}




\begin{tabular}{|c|c|c|c|c|c|c|}
\hline & \multicolumn{6}{|c|}{ Treatment group } \\
\hline & \multicolumn{2}{|c|}{$\begin{array}{l}\text { Statins } \\
N=61,057 \\
\end{array}$} & \multicolumn{2}{|c|}{$\begin{array}{l}\text { Non-statins } \\
N=10,268 \\
\end{array}$} & \multicolumn{2}{|c|}{$\begin{array}{l}\text { No treatment } \\
N=99,134\end{array}$} \\
\hline & Mean & SD & Mean & SD & Mean & SD \\
\hline Heart failure & 9609 & $15.7 \%$ & 1413 & $13.8 \%$ & 9609 & $9.7 \%$ \\
\hline Arrhythmias & 17,517 & $28.7 \%$ & 2605 & $25.4 \%$ & 20,640 & $20.8 \%$ \\
\hline Valvular disease & 9942 & $16.3 \%$ & 1503 & $14.6 \%$ & 11,794 & $11.9 \%$ \\
\hline Pulmonary circulation & 2487 & $4.1 \%$ & 394 & $3.8 \%$ & 3500 & $3.5 \%$ \\
\hline Peripheral vascular & 18,620 & $30.5 \%$ & 2859 & $27.8 \%$ & 18,735 & $18.9 \%$ \\
\hline Hypertension uncomplicated & 42,825 & $70.1 \%$ & 7154 & $69.7 \%$ & 63,465 & $64.0 \%$ \\
\hline Hypertension complicated & 6717 & $11.0 \%$ & 1139 & $11.1 \%$ & 8463 & $8.5 \%$ \\
\hline Paralysis & 653 & $1.1 \%$ & 98 & $1.0 \%$ & 1123 & $1.1 \%$ \\
\hline Other neurological & 4871 & $8.0 \%$ & 752 & $7.3 \%$ & 7784 & $7.9 \%$ \\
\hline Chronic pulmonary & 18,532 & $30.4 \%$ & 2925 & $28.5 \%$ & 25,471 & $25.7 \%$ \\
\hline Diabetes & 20,275 & $33.2 \%$ & 3926 & $38.2 \%$ & 39,227 & $39.6 \%$ \\
\hline Diabetes with end organ damage & 7017 & $11.5 \%$ & 1347 & $13.1 \%$ & 9865 & $10.0 \%$ \\
\hline Hypothyroidism & 8468 & $13.9 \%$ & 1537 & $15.0 \%$ & 17,127 & $17.3 \%$ \\
\hline Renal failure & 7958 & $13.0 \%$ & 1551 & $15.1 \%$ & 9246 & $9.3 \%$ \\
\hline Liver disease & 5132 & $8.4 \%$ & 1009 & $9.8 \%$ & 12,984 & $13.1 \%$ \\
\hline Peptic ulcer disease & 1177 & $1.9 \%$ & 198 & $1.9 \%$ & 2048 & $2.1 \%$ \\
\hline HIV/AIDS & 44 & $0.1 \%$ & 26 & $0.3 \%$ & 449 & $0.5 \%$ \\
\hline Lymphoma & 11,943 & $19.6 \%$ & 2178 & $21.2 \%$ & 20,612 & $20.8 \%$ \\
\hline Metastatic cancer & 9204 & $15.1 \%$ & 1455 & $14.2 \%$ & 17,792 & $17.9 \%$ \\
\hline Solid tumors & 47,821 & $78.3 \%$ & 7837 & $76.3 \%$ & 76,316 & $77.0 \%$ \\
\hline Rheumatoid arthritis & 2972 & $4.9 \%$ & 555 & $5.4 \%$ & 5422 & $5.5 \%$ \\
\hline Coagulopathy & 3414 & $5.6 \%$ & 555 & $5.4 \%$ & 6318 & $6.4 \%$ \\
\hline Obesity & 3161 & $5.2 \%$ & 697 & $6.8 \%$ & 10,027 & $10.1 \%$ \\
\hline Weight loss & 4652 & $7.6 \%$ & 716 & $7.0 \%$ & 8122 & $8.2 \%$ \\
\hline Fluids and electrolytes & 8509 & $13.9 \%$ & 1348 & $13.1 \%$ & 15,904 & $16.0 \%$ \\
\hline Blood loss anemia & 3710 & $6.1 \%$ & 540 & $5.3 \%$ & 5498 & $5.5 \%$ \\
\hline Deficiency anemia & 4884 & $8.0 \%$ & 839 & $8.2 \%$ & 8283 & $8.4 \%$ \\
\hline Alcohol abuse & 487 & $0.8 \%$ & 72 & $0.7 \%$ & 1596 & $1.6 \%$ \\
\hline Drug abuse & 323 & $0.5 \%$ & 50 & $0.5 \%$ & 1080 & $1.1 \%$ \\
\hline Psychoses & 1146 & $1.9 \%$ & 179 & $1.7 \%$ & 1922 & $1.9 \%$ \\
\hline Depression & 4745 & $7.8 \%$ & 806 & $7.8 \%$ & 12,542 & $12.7 \%$ \\
\hline Coronary heart disease & 22,128 & $36.2 \%$ & 3601 & $35.1 \%$ & 24,350 & $24.6 \%$ \\
\hline Myocardial infarction & 4281 & $7.0 \%$ & 626 & $6.1 \%$ & 4912 & $5.0 \%$ \\
\hline Hyperlipidemia & 37,525 & $61.5 \%$ & 6165 & $60.0 \%$ & 72,310 & $72.9 \%$ \\
\hline \multicolumn{7}{|l|}{ Medication use in pre-index } \\
\hline Anticoagulants & 7995 & $13.1 \%$ & 1144 & $11.1 \%$ & 5294 & $5.3 \%$ \\
\hline Antihypertensives & 44,666 & $73.2 \%$ & 6971 & $67.9 \%$ & 31,281 & $31.6 \%$ \\
\hline Antiplatelets & 1013 & $1.7 \%$ & 1510 & $14.7 \%$ & 3544 & $3.6 \%$ \\
\hline Antiarrhythmics & 2275 & $3.7 \%$ & 321 & $3.1 \%$ & 1306 & $1.3 \%$ \\
\hline
\end{tabular}

Thromb Res. Author manuscript; available in PMC 2018 October 01. 


\begin{tabular}{|c|c|c|c|c|c|c|}
\hline & \multicolumn{6}{|c|}{ Treatment group } \\
\hline & \multicolumn{2}{|c|}{$\begin{array}{l}\text { Statins } \\
N=61,057 \\
\end{array}$} & \multicolumn{2}{|c|}{$\begin{array}{l}\text { Non-statins } \\
N=10,268 \\
\end{array}$} & \multicolumn{2}{|c|}{$\begin{array}{l}\text { No treatment } \\
N=99,134\end{array}$} \\
\hline & Mean & SD & Mean & SD & Mean & SD \\
\hline Digoxin & 2960 & $4.8 \%$ & 470 & $4.6 \%$ & 1908 & $1.9 \%$ \\
\hline \multicolumn{7}{|l|}{ Cancer type } \\
\hline Stomach & 1715 & $2.8 \%$ & 267 & $2.6 \%$ & 2904 & $2.9 \%$ \\
\hline Pancreas & 2786 & $4.6 \%$ & 498 & $4.9 \%$ & 5295 & $5.3 \%$ \\
\hline Brain & 1582 & $2.6 \%$ & 283 & $2.8 \%$ & 4135 & $4.2 \%$ \\
\hline Lung & 14,734 & $24.1 \%$ & 2262 & $22.0 \%$ & 17,076 & $17.2 \%$ \\
\hline Kidney & 5881 & $9.6 \%$ & 1092 & $10.6 \%$ & 10,399 & $10.5 \%$ \\
\hline Lymphoma & 9257 & $15.2 \%$ & 1670 & $16.3 \%$ & 16,283 & $16.4 \%$ \\
\hline Leukemia & 5704 & $9.3 \%$ & 1056 & $10.3 \%$ & 8803 & $8.9 \%$ \\
\hline Myeloma & 2801 & $4.6 \%$ & 535 & $5.2 \%$ & 4626 & $4.7 \%$ \\
\hline Colorectal & 12,285 & $20.1 \%$ & 1964 & $19.1 \%$ & 19,660 & $19.8 \%$ \\
\hline Gynecologic & 5517 & $8.8 \%$ & 729 & $8.2 \%$ & 32,303 & $15.0 \%$ \\
\hline
\end{tabular}

\section{Appendix Table 2}

Sub-distribution hazard ratios of venous thromboembolism outcomes in pairwise propensity score matched regression.

\begin{tabular}{|c|c|c|c|c|c|c|c|c|c|c|}
\hline & \multirow[t]{2}{*}{ Outcome $^{*}$} & \multicolumn{3}{|c|}{$\underline{\text { Statins vs. non-statins }}$} & \multicolumn{3}{|c|}{ Statins vs. no treatment } & \multicolumn{3}{|c|}{$\begin{array}{l}\text { Non-statins vs. no } \\
\text { treatment } \\
\end{array}$} \\
\hline & & sdHR & $\mathbf{9 5 \%} \mathrm{CI}$ & & sdHR & $95 \% \mathrm{CI}$ & & sdHR & $95 \% \mathrm{CI}$ & \\
\hline \multirow[t]{4}{*}{ All cancers } & DVT (general) & 0.96 & 0.88 & 1.05 & 0.93 & 0.89 & 0.97 & 1.02 & 0.93 & 1.12 \\
\hline & PE (general) & 0.91 & 0.79 & 1.05 & 0.95 & 0.88 & 1.01 & 1.00 & 0.87 & 1.16 \\
\hline & DVT (specific) & 0.98 & 0.89 & 1.08 & 0.93 & 0.89 & 0.97 & 1.01 & 0.91 & 1.11 \\
\hline & PE (specific) & 0.92 & 0.80 & 1.06 & 0.95 & 0.89 & 1.02 & 1.01 & 0.87 & 1.16 \\
\hline \multirow[t]{4}{*}{ Stomach } & DVT (general) & 1.40 & 0.93 & 2.09 & 0.91 & 0.76 & 1.10 & 0.82 & 0.53 & 1.25 \\
\hline & PE (general) & 1.17 & 0.67 & 2.05 & 0.94 & 0.73 & 1.20 & 1.01 & 0.55 & 1.84 \\
\hline & DVT (specific) & 1.41 & 0.91 & 2.20 & 0.89 & 0.74 & 1.08 & 0.76 & 0.48 & 1.19 \\
\hline & PE (specific) & 1.17 & 0.67 & 2.05 & 0.94 & 0.73 & 1.20 & 1.01 & 0.55 & 1.84 \\
\hline \multirow[t]{4}{*}{ Pancreas } & DVT (general) & 0.92 & 0.68 & 1.25 & 1.09 & 0.94 & 1.26 & 1.28 & 0.94 & 1.75 \\
\hline & PE (general) & 1.22 & 0.70 & 2.11 & 1.00 & 0.80 & 1.26 & 0.80 & 0.46 & 1.37 \\
\hline & DVT (specific) & 0.90 & 0.67 & 1.22 & 1.12 & 0.97 & 1.30 & 1.32 & 0.96 & 1.81 \\
\hline & PE (specific) & 1.22 & 0.70 & 2.11 & 1.02 & 0.81 & 1.28 & 0.81 & 0.47 & 1.39 \\
\hline \multirow[t]{4}{*}{ Brain } & DVT (general) & 1.03 & 0.65 & 1.66 & 1.18 & 0.95 & 1.46 & 1.05 & 0.62 & 1.77 \\
\hline & PE (general) & 0.78 & 0.40 & 1.53 & 1.21 & 0.86 & 1.70 & 1.12 & 0.51 & 2.49 \\
\hline & DVT (specific) & 1.05 & 0.64 & 1.72 & 1.17 & 0.94 & 1.46 & 1.06 & 0.62 & 1.83 \\
\hline & PE (specific) & 0.78 & 0.40 & 1.53 & 1.21 & 0.86 & 1.70 & 1.12 & 0.51 & 2.49 \\
\hline \multirow[t]{3}{*}{ Lung } & DVT (general) & 0.93 & 0.77 & 1.12 & 0.95 & 0.86 & 1.03 & 1.08 & 0.89 & 1.32 \\
\hline & PE (general) & 0.82 & 0.65 & 1.05 & 0.91 & 0.81 & 1.03 & 1.06 & 0.82 & 1.35 \\
\hline & DVT (specific) & 0.97 & 0.79 & 1.19 & 0.94 & 0.85 & 1.03 & 1.07 & 0.87 & 1.32 \\
\hline
\end{tabular}

Thromb Res. Author manuscript; available in PMC 2018 October 01. 


\begin{tabular}{|c|c|c|c|c|c|c|c|c|c|c|}
\hline & \multirow{3}{*}{$\begin{array}{l}\text { Outcome }^{*} \\
\text { PE (specific) }\end{array}$} & \multicolumn{3}{|c|}{ Statins vs. non-statins } & \multicolumn{3}{|c|}{ Statins vs. no treatment } & \multicolumn{3}{|c|}{$\begin{array}{l}\text { Non-statins vs. no } \\
\text { treatment }\end{array}$} \\
\hline & & \multirow{2}{*}{$\begin{array}{l}\mathbf{S d H R} \\
0.82\end{array}$} & \multicolumn{2}{|l|}{$95 \% \mathrm{CI}$} & \multirow{2}{*}{$\begin{array}{l}\text { SdHR } \\
0.91\end{array}$} & \multicolumn{2}{|l|}{$95 \% \mathrm{CI}$} & \multirow{2}{*}{$\begin{array}{l}\text { sdHR } \\
1.07\end{array}$} & \multicolumn{2}{|l|}{$95 \% \mathrm{CI}$} \\
\hline & & & 0.64 & 1.04 & & 0.81 & 1.03 & & 0.83 & 1.37 \\
\hline \multirow[t]{4}{*}{ Renal } & DVT (general) & 1.19 & 0.82 & 1.74 & 0.89 & 0.75 & 1.06 & 0.86 & 0.59 & 1.25 \\
\hline & $\mathrm{PE}$ (general) & 1.02 & 0.54 & 1.93 & 0.86 & 0.64 & 1.15 & 1.10 & 0.60 & 2.00 \\
\hline & DVT (specific) & 1.12 & 0.77 & 1.63 & 0.90 & 0.75 & 1.07 & 0.99 & 0.67 & 1.46 \\
\hline & PE (specific) & 1.02 & 0.54 & 1.93 & 0.86 & 0.64 & 1.15 & 1.10 & 0.60 & 2.00 \\
\hline \multirow[t]{4}{*}{ Lymphoma } & DVT (general) & 0.77 & 0.60 & 1.00 & 0.91 & 0.80 & 1.04 & 1.23 & 0.94 & 1.62 \\
\hline & $\mathrm{PE}$ (general) & 0.78 & 0.51 & 1.19 & 1.02 & 0.81 & 1.27 & 1.50 & 0.94 & 2.41 \\
\hline & DVT (specific) & 0.75 & 0.57 & 0.99 & 0.90 & 0.79 & 1.03 & 1.24 & 0.93 & 1.65 \\
\hline & PE (specific) & 0.78 & 0.51 & 1.19 & 1.02 & 0.82 & 1.27 & 1.50 & 0.94 & 2.41 \\
\hline \multirow[t]{4}{*}{ Leukemia } & DVT (general) & 0.91 & 0.62 & 1.33 & 0.83 & 0.69 & 0.99 & 1.04 & 0.71 & 1.51 \\
\hline & $\mathrm{PE}$ (general) & 0.78 & 0.41 & 1.48 & 0.77 & 0.54 & 1.09 & 1.38 & 0.74 & 2.57 \\
\hline & DVT (specific) & 1.03 & 0.67 & 1.58 & 0.78 & 0.64 & 0.95 & 0.83 & 0.55 & 1.26 \\
\hline & PE (specific) & 0.84 & 0.43 & 1.64 & 0.80 & 0.56 & 1.14 & 1.33 & 0.72 & 2.47 \\
\hline \multirow[t]{4}{*}{ Myeloma } & DVT (general) & 1.33 & 0.84 & 2.09 & 0.86 & 0.71 & 1.04 & 0.80 & 0.51 & 1.25 \\
\hline & PE (general) & 2.85 & 0.89 & 9.18 & 0.95 & 0.67 & 1.33 & 0.38 & 0.13 & 1.14 \\
\hline & DVT (specific) & 1.38 & 0.84 & 2.28 & 0.89 & 0.73 & 1.08 & 0.79 & 0.49 & 1.26 \\
\hline & PE (specific) & 2.85 & 0.89 & 9.18 & 0.94 & 0.67 & 1.33 & 0.41 & 0.13 & 1.24 \\
\hline \multirow[t]{4}{*}{ Colorectal } & DVT (general) & 0.88 & 0.71 & 1.09 & 0.84 & 0.76 & 0.93 & 0.92 & 0.73 & 1.15 \\
\hline & $\mathrm{PE}$ (general) & 0.89 & 0.60 & 1.31 & 0.83 & 0.69 & 0.99 & 0.74 & 0.50 & 1.09 \\
\hline & DVT (specific) & 0.95 & 0.75 & 1.19 & 0.88 & 0.79 & 0.97 & 0.91 & 0.71 & 1.15 \\
\hline & PE (specific) & 0.92 & 0.62 & 1.37 & 0.83 & 0.69 & 1.00 & 0.71 & 0.48 & 1.06 \\
\hline \multirow[t]{4}{*}{ Gynecologic } & DVT (general) & 1.11 & 0.78 & 1.58 & 0.97 & 0.84 & 1.11 & 1.00 & 0.69 & 1.45 \\
\hline & PE (general) & 0.94 & 0.54 & 1.62 & 1.11 & 0.89 & 1.38 & 1.31 & 0.69 & 2.49 \\
\hline & DVT (specific) & 1.14 & 0.79 & 1.67 & 0.96 & 0.82 & 1.11 & 0.94 & 0.63 & 1.40 \\
\hline & PE (specific) & 0.94 & 0.54 & 1.62 & 1.12 & 0.90 & 1.39 & 1.37 & 0.72 & 2.59 \\
\hline
\end{tabular}

Abbreviations: $\mathrm{DVT}=$ deep vein thrombosis; $\mathrm{PE}=$ pulmonary embolism.

* General and specific outcomes refer to the ICD-9 code definition used for each outcome.

Appendix Table 3

Cause-specific hazard ratios of venous thromboembolism using a broad coding definition for outcome events.

\begin{tabular}{|c|c|c|c|c|c|c|c|c|c|c|}
\hline & & \multicolumn{3}{|c|}{$\underline{\text { Statins vs. non-statins }}$} & \multicolumn{3}{|c|}{ Statins vs. no treatment } & \multicolumn{3}{|c|}{$\begin{array}{l}\text { Non-statins vs. no } \\
\text { treatment }\end{array}$} \\
\hline & & csHR & $95 \% \mathrm{CI}$ & & csHR & $95 \%$ CI & & csHR & $95 \% \mathrm{CI}$ & \\
\hline \multirow[t]{2}{*}{ All cancers } & DVT (general) & 0.97 & 0.89 & 1.06 & 0.92 & 0.87 & 0.98 & 0.94 & 0.86 & 1.02 \\
\hline & PE (general) & 0.94 & 0.82 & 1.07 & 0.94 & 0.87 & 1.03 & 1.01 & 0.88 & 1.16 \\
\hline \multirow[t]{2}{*}{ Stomach } & DVT (general) & 1.30 & 0.88 & 1.90 & 0.88 & 0.70 & 1.10 & 0.72 & 0.49 & 1.06 \\
\hline & PE (general) & 1.20 & 0.69 & 2.08 & 0.98 & 0.72 & 1.34 & 0.65 & 0.37 & 1.13 \\
\hline \multirow[t]{2}{*}{ Pancreas } & DVT (general) & 0.80 & 0.61 & 1.05 & 1.04 & 0.87 & 1.24 & 1.31 & 0.99 & 1.73 \\
\hline & PE (general) & 1.10 & 0.68 & 1.78 & 0.89 & 0.68 & 1.17 & 1.20 & 0.73 & 1.97 \\
\hline
\end{tabular}

Thromb Res. Author manuscript; available in PMC 2018 October 01. 


\begin{tabular}{|c|c|c|c|c|c|c|c|c|c|c|}
\hline \multirow[b]{3}{*}{ Brain } & \multirow[b]{3}{*}{ DVT (general) } & \multicolumn{3}{|c|}{$\underline{\text { Statins vs. non-statins }}$} & \multicolumn{3}{|c|}{ Statins vs. no treatment } & \multicolumn{3}{|c|}{$\begin{array}{l}\text { Non-statins vs. no } \\
\text { treatment }\end{array}$} \\
\hline & & \multirow{2}{*}{$\begin{array}{l}\text { csHR } \\
0.95\end{array}$} & \multicolumn{2}{|l|}{ 95\% CI } & \multirow{2}{*}{$\frac{\text { csHR }}{1.04}$} & \multicolumn{2}{|l|}{$95 \% \mathrm{CI}$} & \multirow{2}{*}{$\frac{\text { csHR }}{}$} & \multicolumn{2}{|l|}{ 95\% CI } \\
\hline & & & 0.61 & 1.48 & & 0.80 & 1.37 & & 0.53 & 1.47 \\
\hline & $\mathrm{PE}$ (general) & 0.83 & 0.43 & 1.60 & 1.11 & 0.74 & 1.66 & 0.97 & 0.48 & 1.95 \\
\hline \multirow[t]{2}{*}{ Lung } & DVT (general) & 0.97 & 0.81 & 1.16 & 0.92 & 0.82 & 1.03 & 1.01 & 0.84 & 1.21 \\
\hline & PE (general) & 0.79 & 0.64 & 0.99 & 0.94 & 0.81 & 1.10 & 1.13 & 0.90 & 1.43 \\
\hline \multirow[t]{2}{*}{ Renal } & DVT (general) & 1.27 & 0.88 & 1.83 & 0.90 & 0.73 & 1.12 & 0.72 & 0.50 & 1.05 \\
\hline & PE (general) & 1.30 & 0.68 & 2.48 & 0.91 & 0.63 & 1.32 & 0.96 & 0.52 & 1.76 \\
\hline \multirow[t]{2}{*}{ Lymphoma } & DVT (general) & 0.86 & 0.67 & 1.09 & 0.88 & 0.75 & 1.04 & 1.03 & 0.80 & 1.32 \\
\hline & $\mathrm{PE}$ (general) & 0.76 & 0.50 & 1.14 & 1.07 & 0.80 & 1.42 & 1.42 & 0.92 & 2.18 \\
\hline \multirow[t]{2}{*}{ Leukemia } & DVT (general) & 0.91 & 0.64 & 1.29 & 0.85 & 0.68 & 1.06 & 0.95 & 0.67 & 1.35 \\
\hline & PE (general) & 0.74 & 0.41 & 1.35 & 0.89 & 0.57 & 1.39 & 1.03 & 0.58 & 1.85 \\
\hline \multirow[t]{2}{*}{ Myeloma } & DVT (general) & 1.23 & 0.83 & 1.84 & 0.99 & 0.78 & 1.25 & 0.82 & 0.54 & 1.23 \\
\hline & PE (general) & 1.91 & 0.79 & 4.61 & 1.07 & 0.68 & 1.69 & 0.66 & 0.25 & 1.73 \\
\hline \multirow[t]{2}{*}{ Colorectal } & DVT (general) & 0.92 & 0.75 & 1.13 & 0.87 & 0.76 & 0.98 & 0.87 & 0.71 & 1.08 \\
\hline & PE (general) & 0.98 & 0.67 & 1.42 & 0.80 & 1.00 & 1.00 & 0.86 & 0.59 & 1.25 \\
\hline \multirow[t]{2}{*}{ Gynecologic } & DVT (general) & 1.08 & 0.78 & 1.49 & 1.07 & 0.89 & 1.30 & 0.84 & 0.58 & 1.21 \\
\hline & PE (general) & 1.06 & 0.65 & 1.72 & 1.07 & 0.80 & 1.44 & 1.06 & 0.61 & 1.83 \\
\hline
\end{tabular}

Abbreviations: $\mathrm{csHR}=$ cause-specific hazard ratio; DVT = deep vein thrombosis; $\mathrm{PE}=$ pulmonary embolism.

\section{Appendix Table 4}

Follow-up time and number of events for treatment cohorts in each matched comparison.

\begin{tabular}{|c|c|c|c|c|c|c|}
\hline Treatment group & $\mathbf{N}$ & Follow-up time (person-years) & Event & Number of events & $\%$ with event & $\begin{array}{l}\text { Incidence per } \\
1000 \text { person- } \\
\text { years }(95 \% \mathrm{CI})\end{array}$ \\
\hline \multicolumn{7}{|c|}{ Statins vs. non-statins } \\
\hline \multirow[t]{4}{*}{ Statins } & 51,983 & $33,469.5$ & DVT (specific) & 2410 & $4.64 \%$ & $72(69.2-74.9)$ \\
\hline & & & DVT (general) & 2646 & $5.09 \%$ & $79.1(76.1-82.1)$ \\
\hline & & & PE (specific) & 1113 & $2.14 \%$ & $33.3(31.3-35.3)$ \\
\hline & & & PE (general) & 1116 & $2.15 \%$ & $33.3(31.4-35.3)$ \\
\hline \multirow[t]{4}{*}{ Non-statins } & 15,334 & 8240.2 & DVT (specific) & 587 & $3.83 \%$ & $71.2(65.6-77.2)$ \\
\hline & & & DVT (general) & 657 & $4.28 \%$ & $79.7(73.8-86.0)$ \\
\hline & & & PE (specific) & 284 & $1.85 \%$ & $34.5(30.6-38.7)$ \\
\hline & & & PE (general) & 286 & $1.87 \%$ & $34.7(30.9-38.9)$ \\
\hline \multicolumn{7}{|c|}{ Statins vs. no treatment } \\
\hline \multirow[t]{4}{*}{ Statins } & 39,821 & $31,716.6$ & DVT (specific) & 2306 & $5.79 \%$ & $72.7(69.8-75.7)$ \\
\hline & & & DVT (general) & 2536 & $6.37 \%$ & $80(76.9-83.1)$ \\
\hline & & & PE (specific) & 1060 & $2.66 \%$ & $33.4(31.5-35.5)$ \\
\hline & & & PE (general) & 1063 & $2.67 \%$ & $33.5(31.6-35.6)$ \\
\hline \multirow[t]{4}{*}{ No treatment } & 39,821 & $31,298.2$ & DVT (specific) & 2507 & $6.30 \%$ & $80.1(77.0-83.3)$ \\
\hline & & & DVT (general) & 2737 & $6.87 \%$ & $87.4(84.2-90.8)$ \\
\hline & & & PE (specific) & 1113 & $2.80 \%$ & $35.6(33.5-37.7)$ \\
\hline & & & PE (general) & 1139 & $2.86 \%$ & $36.4(34.9-36.3)$ \\
\hline
\end{tabular}

Thromb Res. Author manuscript; available in PMC 2018 October 01. 


\begin{tabular}{lllllll}
\hline Treatment group & $\mathbf{N}$ & Follow-up time (person-years) & Event & Number of events & $\%$ with event & $\begin{array}{l}\text { Incidence per } \\
\text { 1000 person- } \\
\text { years (95\% CI) }\end{array}$ \\
\hline Non-statins vs. no treatment & & & & & & \\
Non-statins & 10,621 & 8333.3 & DVT (specific) & 596 & $5.61 \%$ & $71.5(66.0-77.4)$ \\
& & & DVT (general) & 668 & $6.29 \%$ & $80.2(74.3-86.4)$ \\
& & & PE (specific) & 288 & $2.71 \%$ & $34.6(30.7-38.7)$ \\
No treatment & \multirow{2}{*}{37,098} & $23,390.7$ & PE (general) & 290 & $2.73 \%$ & $34.8(31.0-39.0)$ \\
& & & DVT (specific) & 1848 & $4.98 \%$ & $79(75.5-82.7)$ \\
& & & DVT (general) & 2025 & $5.46 \%$ & $86.6(82.9-90.4)$ \\
& & & PE (specific) & 823 & $2.22 \%$ & $35.2(32.8-37.7)$ \\
& & PE (general) & 828 & $2.23 \%$ & $35.4(33.1-37.9)$ \\
\hline
\end{tabular}

"General" outcomes refer to a broader coding definition using ICD-9451.xx and 453.xx for DVT and 415.1x for PE. "Specific" outcome definitions are based on a more validated subset of codes within these codes.

Abbreviations: deep vein thrombosis (DVT); pulmonary embolism (PE); confidence interval (CI).

\section{References}

1. Hisada Y, Geddings JE, Ay C, Mackman N. Venous thrombosis and cancer: from mouse models to clinical trials. J Thromb Haemost. 2015; 13(8):1372-1382. http://dx.doi.org/10.1111/jth.13009. [PubMed: 25988873]

2. Timp JF, Braekkan SK, Versteeg HH, Cannegieter SC. Epidemiology of cancer-associated venous thrombosis. Blood. 2013; 122(10):1712-1723. http://dx.doi.org/10.1182/blood-2013-04-460121. [PubMed: 23908465]

3. Blom JW, Doggen CJ, Osanto S, Rosendaal FR. Malignancies, prothrombotic mutations, and the risk of venous thrombosis. JAMA. 2005; 293(6):715-722. doi: 293/6/715 pii. [PubMed: 15701913]

4. Cronin-Fenton DP, Sondergaard F, Pedersen LA, et al. Hospitalisation for venous thromboembolism in cancer patients and the general population: a population-based cohort study in Denmark, 19972006. Br J Cancer. 2010; 103(7):947-953. http://dx.doi.org/10.1038/sj.bjc.6605883. [PubMed: 20842120]

5. Heit JA, Silverstein MD, Mohr DN, Petterson TM, O’Fallon WM, Melton LJ 3rd. Risk factors for deep vein thrombosis and pulmonary embolism: a population-based case-control study. Arch Intern Med. 2000; 160(6):809-815. [PubMed: 10737280]

6. Lip GY, Chin BS, Blann AD. Cancer and the prothrombotic state. Lancet Oncol. 2002; 3(1):27-34. [PubMed: 11908507]

7. Horsted F, West J, Grainge MJ. Risk of venous thromboembolism in patients with cancer: a systematic review and meta-analysis. PLoS Med. 2012; 9(7):e1001275. http://dx.doi.org/10.1371/ journal.pmed.1001275. [PubMed: 22859911]

8. Khorana AA, Kuderer NM, Culakova E, Lyman GH, Francis CW. Development and validation of a predictive model for chemotherapy-associated thrombosis. Blood. 2008; 111(10):4902-4907. http:// dx.doi.org/10.1182/blood-2007-10-116327. [PubMed: 18216292]

9. Frere C, Debourdeau P, Hij A, et al. Therapy for cancer-related thromboembolism. Semin Oncol. 2014; 41(3):319-338. http://dx.doi.org/10.1053/j.seminoncol.2014.04.005. [PubMed: 25023348]

10. Khorana AA, Francis CW, Culakova E, Kuderer NM, Lyman GH. Thromboembolism is a leading cause of death in cancer patients receiving outpatient chemotherapy. J Thromb Haemost. 2007; 5(3):632-634. doi: JTH2374 [pii. [PubMed: 17319909]

11. Khorana AA. Venous thromboembolism and prognosis in cancer. Thromb Res. 2010; 125(6):490493. http://dx.doi.org/10.1016/j.thromres.2009.12.023. [PubMed: 20097409]

12. Schmidt M, Cannegieter SC, Johannesdottir SA, Dekkers OM, Horvath-Puho E, Sorensen HT. Statin use and venous thromboembolism recurrence: a combined nationwide cohort and nested 
case-control study. J Thromb Haemost. 2014; 12(8):1207-1215. http://dx.doi.org/10.1111/jth. 12604. [PubMed: 24818818]

13. Wells PS, Gebel M, Prins MH, Davidson BL, Lensing AW. Influence of statin use on the incidence of recurrent venous thromboembolism and major bleeding in patients receiving rivaroxaban or standard anticoagulant therapy. Thromb J. 2014; 12(1):1. [PubMed: 24383745]

14. Rodriguez AL, Wojcik BM, Wrobleski SK, Myers DD Jr, Wakefield TW, Diaz JA. Statins, inflammation and deep vein thrombosis: a systematic review. J Thromb Thrombolysis. 2012; 33(4):371-382. http://dx.doi.org/10.1007/s11239-012-0687-9. [PubMed: 22278047]

15. Rahimi K, Bhala N, Kamphuisen P, et al. Effect of statins on venous thromboembolic events: a meta-analysis of published and unpublished evidence from randomised controlled trials. PLoS Med. 2012; 9(9):e1001310. http://dx.doi.org/10.1371/journal.pmed.1001310. [PubMed: 23028261]

16. Rabinowich L, Steinvil A, Leshem-Rubinow E, et al. Adherence to statins is associated with reduced incidence of idiopathic venous thromboembolism: real-life data from a large healthcare maintenance organisation. Heart. 2012; 98(24):1817-1821. http://dx.doi.org/10.1136/ heartjnl-2012-302906. [PubMed: 23038788]

17. Glynn RJ, Danielson E, Fonseca FA, et al. A randomized trial of rosuvastatin in the prevention of venous thromboembolism. N Engl J Med. 2009; 360(18):1851-1861. http://dx.doi.org/10.1056/ NEJMoa0900241. [PubMed: 19329822]

18. Lassila R, Jula A, Pitkaniemi J, Haukka J. The association of statin use with reduced incidence of venous thromboembolism: a population-based cohort study. BMJ Open. 2014; 4(11) e005862-2014-005862. http://dx.doi.org/10.1136/bmjopen-2014-005862.

19. Macedo AF, Taylor FC, Casas JP, Adler A, Prieto-Merino D, Ebrahim S. Unintended effects of statins from observational studies in the general population: systematic review and meta-analysis. BMC Med. 2014; 12 51-7015-12-51. http://dx.doi.org/10.1186/1741-7015-12-51.

20. Khemasuwan D, Divietro ML, Tangdhanakanond K, Pomerantz SC, Eiger G. Statins decrease the occurrence of venous thromboembolism in patients with cancer. Am J Med. 2010; 123(1):60-65. http://dx.doi.org/10.1016/j.amjmed.2009.05.025. [PubMed: 20102993]

21. Khemasuwan D, Chae YK, Gupta S, et al. Dose-related effect of statins in venous thrombosis risk reduction. Am J Med. 2011; 124(9):852-859. http://dx.doi.org/10.1016/j.amjmed.2011.04.019. [PubMed: 21783169]

22. Nguyen CD, Andersson C, Jensen TB, et al. Statin treatment and risk of recurrent venous thromboembolism: a nationwide cohort study. BMJ Open. 2013; 3(11) e003135-2013-003135. http://dx.doi.org/10.1136/bmjopen-2013-003135.

23. Lotsch F, Konigsbrugge O, Posch F, Zielinski C, Pabinger I, Ay C. Statins are associated with low risk of venous thromboembolism in patients with cancer: a prospective and observational cohort study. Thromb Res. 2014; 134(5):1008-1013. http://dx.doi.org/10.1016/j.thromres.2014.09.001. [PubMed: 25234407]

24. Bu DX, Griffin G, Lichtman AH. Mechanisms for the anti-inflammatory effects of statins. Curr Opin Lipidol. 2011; 22(3):165-170. http://dx.doi.org/10.1097/MOL.0b013e3283453e41. [PubMed: 21412153]

25. Davignon J. Beneficial cardiovascular pleiotropic effects of statins. Circulation. 2004; 109(23 Suppl 1):III39-43. http://dx.doi.org/10.1161/01.CIR.0000131517.20177.5a. [PubMed: 15198965]

26. Herrington DM, Vittinghoff E, Lin F, et al. Statin therapy, cardiovascular events, and total mortality in the heart and estrogen/progestin replacement study (HERS). Circulation. 2002; 105(25):29622967. [PubMed: 12081988]

27. Tagalakis V, Eberg M, Kahn S, Azoulay L, et al. Use of statins and reduced risk of recurrence of VTE in an older population. Thromb Haemost. 2016 Jun 2; 115(6):1220-1228. http://dx.doi.org/ 10.1160/TH15-10-0775 Epub 2016 Jan 28. [PubMed: 26819144]

28. Charlson ME, Charlson RE, Peterson JC, Marinopoulos SS, Briggs WM, Hollenberg JP. The charlson comorbidity index is adapted to predict costs of chronic disease in primary care patients. $\mathrm{J}$ Clin Epidemiol. 2008; 61(12):1234-1240. http://dx.doi.org/10.1016/j.jclinepi.2008.01.006. [PubMed: 18619805] 
29. Quan H, Sundararajan V, Halfon P, et al. Coding algorithms for defining comorbidities in ICD-9CM and ICD-10 administrative data. Med Care. 2005; 43(11):1130-1139. [PubMed: 16224307]

30. Elixhauser, A., Steiner, C., Kruzikas, D. Comorbidity software documentation. 2004. HCUP methods series report \#2004-1http://www.hcup-us.ahrq.gov/toolssoftware/co-morbidity/ comorbidity.jspAccessed date: January 2014 (Updated 2004)

31. Zhan C, Battles J, Chiang YP, Hunt D. The validity of ICD-9-CM codes in identifying postoperative deep vein thrombosis and pulmonary embolism, Jt. Comm. J Qual Patient Saf. 2007; 33(6):326-331.

32. White RH, Garcia M, Sadeghi B, et al. Evaluation of the predictive value of ICD-9-CM coded administrative data for venous thromboembolism in the United States. Thromb Res. 2010; 126(1): 61-67. http://dx.doi.org/10.1016/j.thromres.2010.03.009. [PubMed: 20430419]

33. Austin PC. An introduction to propensity score methods for reducing the effects of confounding in observational studies. Multivar Behav Res. 2011; 46(3):399-424. http://dx.doi.org/ 10.1080/00273171.2011.568786.

34. Rosenbaum PR, Rubin DB. The central role of the propensity score in observational studies for causal effects. Biometrika. 1983; 70(1):41-55.

35. Austin PC. Balance diagnostics for comparing the distribution of baseline covariates between treatment groups in propensity-score matched samples. Stat Med. 2009; 28(25):3083-3107. http:// dx.doi.org/10.1002/sim.3697. [PubMed: 19757444]

36. Austin PC, Lee DS, Fine JP. Introduction to the analysis of survival data in the presence of competing risks. Circulation. 2016; 133(6):601-609. http://dx.doi.org/10.1161/ CIRCULATIONAHA.115.017719. [PubMed: 26858290]

38. Farge D, Bounameaux H, Brenner B, et al. International clinical practice guidelines including guidance for direct oral anticoagulants in the treatment and prophylaxis of venous thromboembolism in patients with cancer. Lancet Oncol. 2016; 17(10):e452-e466. (doi: S1470-2045(16)30369-2 [pii). [PubMed: 27733271]

39. Lohinai Z, Dome P, Szilagyi Z, et al. From bench to bedside: attempt to evaluate repositioning of drugs in the treatment of metastatic small cell lung cancer (SCLC). PLoS One. 2016; 11(1):e0144797. http://dx.doi.org/10.1371/journal.pone.0144797. [PubMed: 26735301]

40. Demierre MF, Higgins PD, Gruber SB, Hawk E, Lippman SM. Statins and cancer prevention. Nat Rev Cancer. 2005; 5(12):930-942. (doi: nrc1751 [pii). [PubMed: 16341084]

41. Zhang FL, Casey PJ. Protein prenylation: molecular mechanisms and functional consequences. Annu Rev Biochem. 1996; 65:241-269. http://dx.doi.org/10.1146/annurev.bi.65.070196.001325. [PubMed: 8811180]

42. Chang L, Mammalian Karin M. MAP kinase signalling cascades. Nature. 2001; 410(6824):37-40. http://dx.doi.org/10.1038/35065000. [PubMed: 11242034]

43. Schneeweiss S, Avorn J. A review of uses of health care utilization databases for epidemiologic research on therapeutics. J Clin Epidemiol. 2005; 58(4):323-337. (doi: S0895-4356(04)00298-7 [pii). [PubMed: 15862718]

44. Zhan C, Miller MR. Administrative data based patient safety research: a critical review. Qual Saf Health Care. 2003; 12(Suppl. 2):ii58-63. [PubMed: 14645897] 

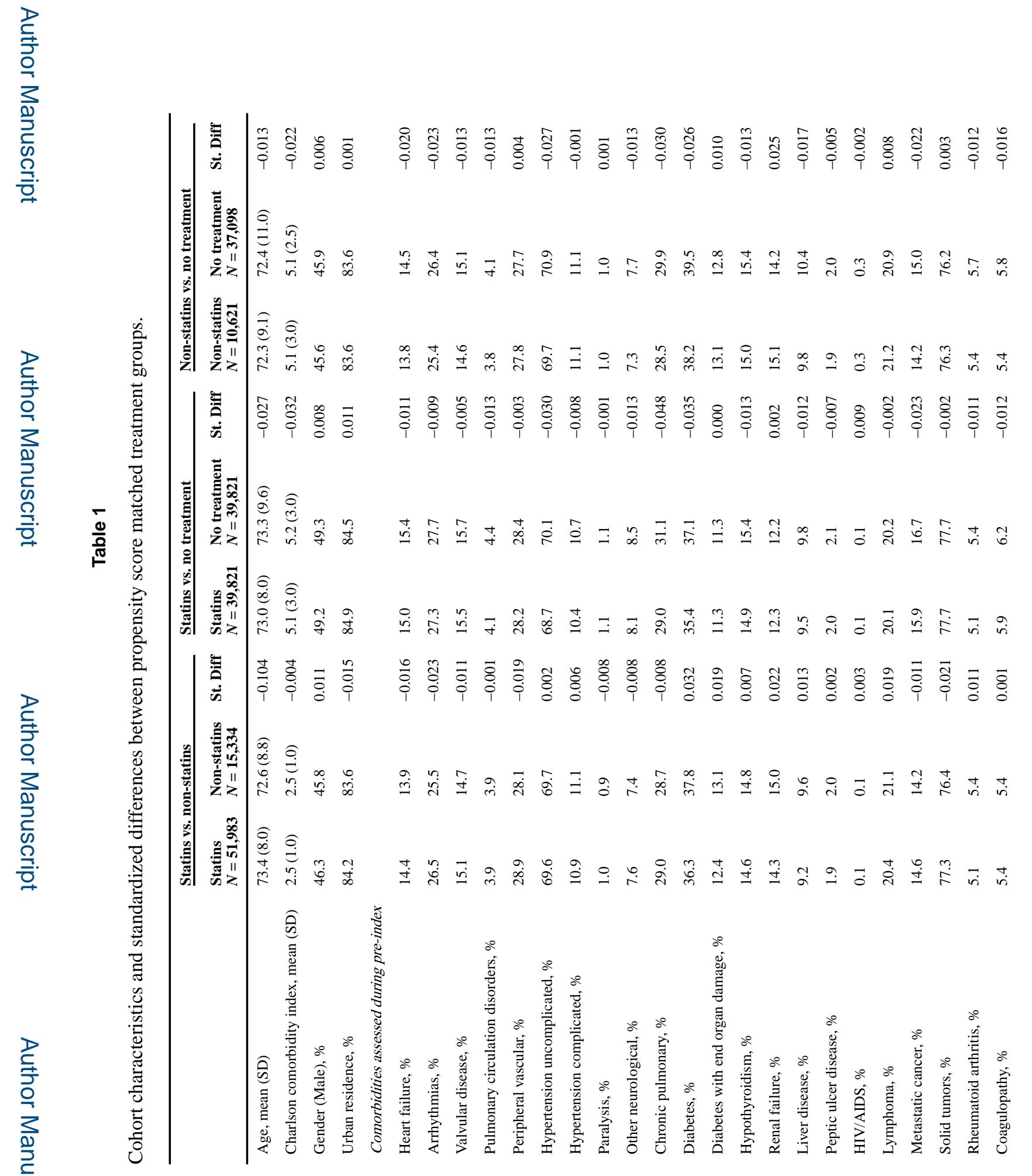

Thromb Res. Author manuscript; available in PMC 2018 October 01. 
El-Refai et al.

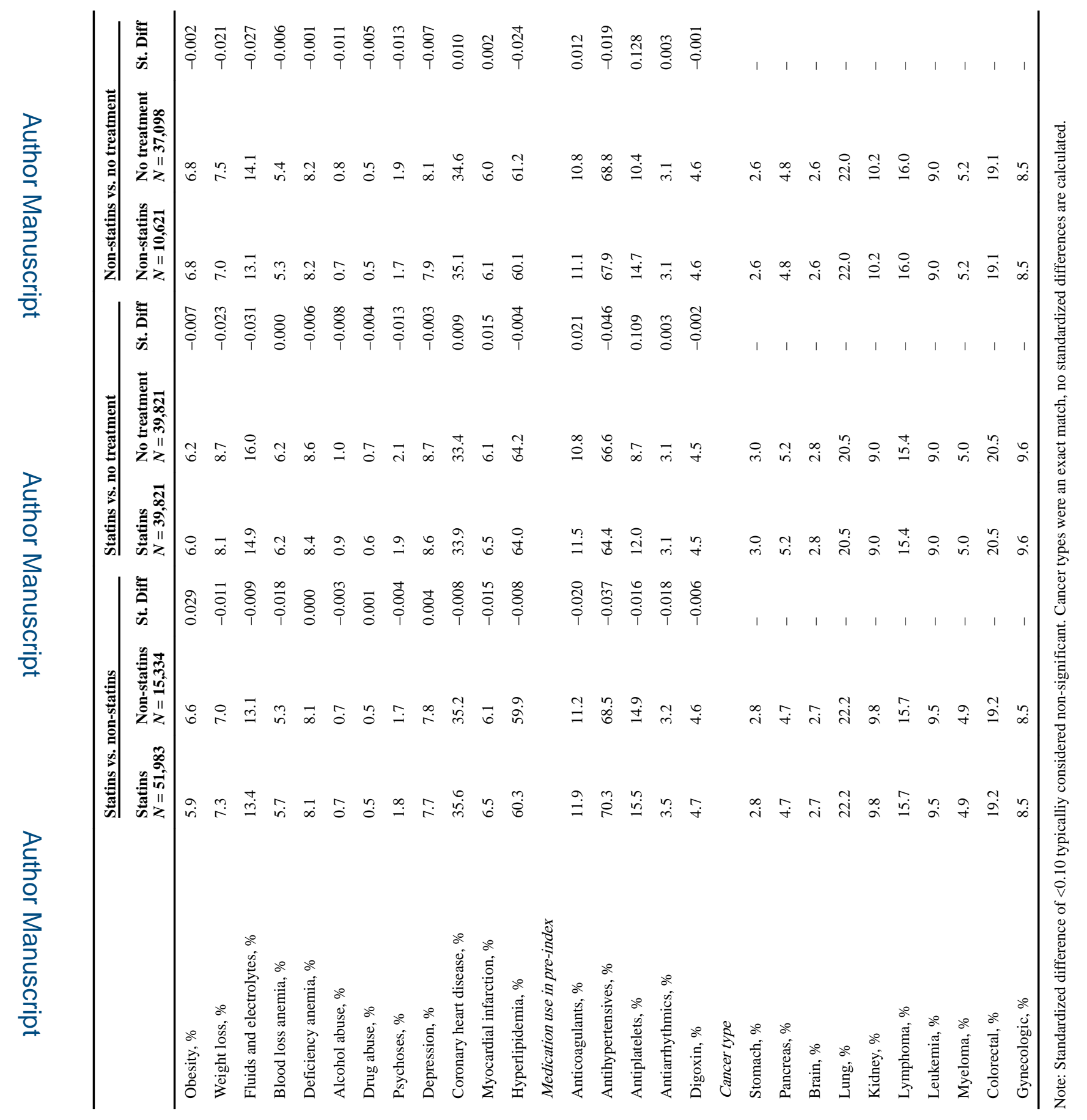

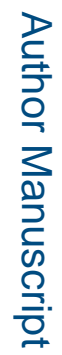

Thromb Res. Author manuscript; available in PMC 2018 October 01. 

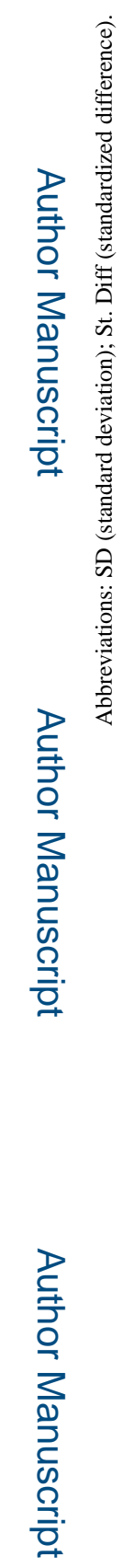

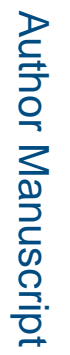

Thromb Res. Author manuscript; available in PMC 2018 October 01. 


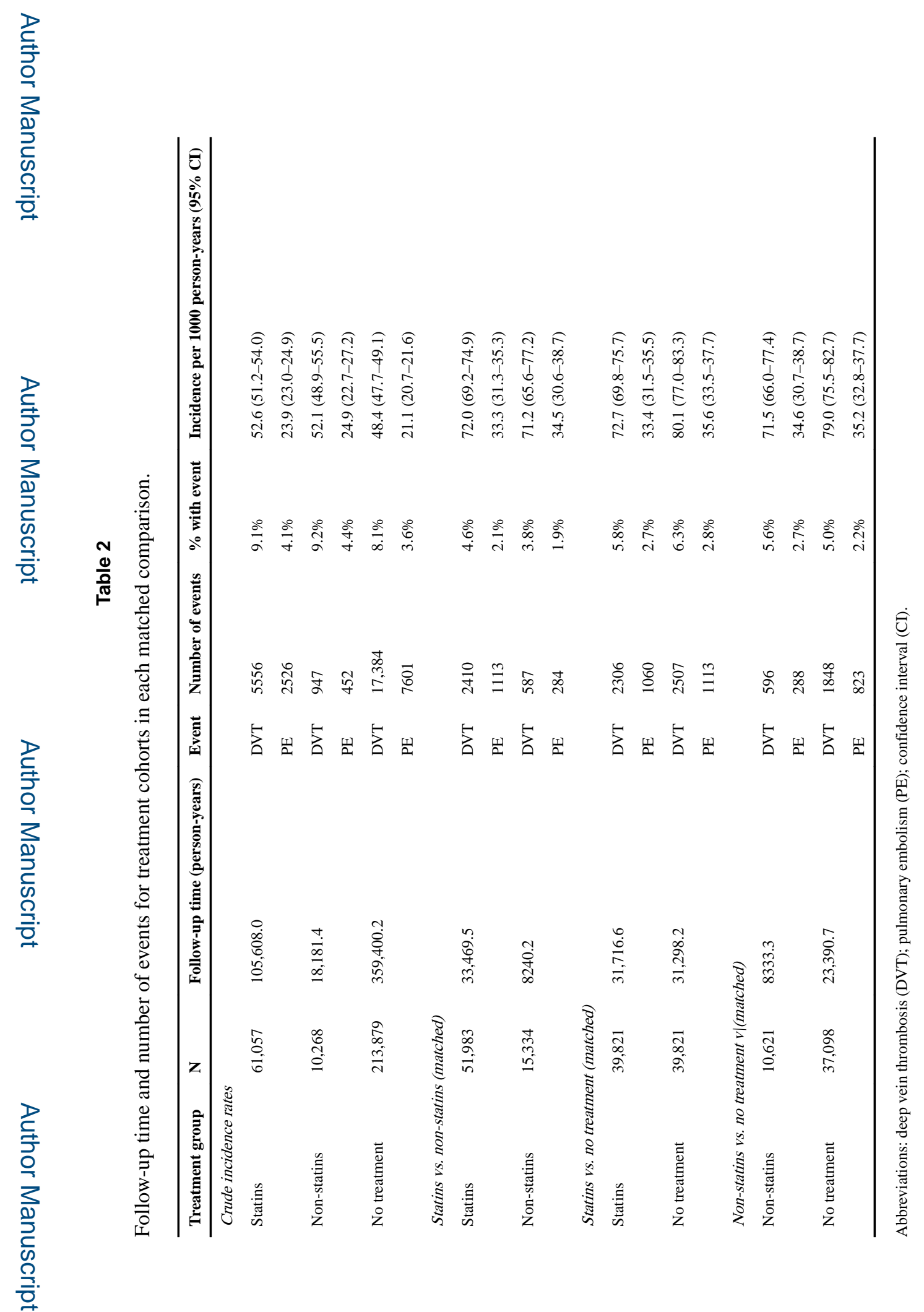

Thromb Res. Author manuscript; available in PMC 2018 October 01. 


\section{Table 3}

Cause-specific hazard ratio of risk for deep vein thrombosis and pulmonary embolism in the overall and cancer-stratified regression models in propensity score matched treatment groups.

\begin{tabular}{|c|c|c|c|}
\hline & & Deep vein thrombosis & Pulmonary embolism \\
\hline \multirow[t]{11}{*}{ Statins Vs. non-statins } & All cancers & $0.99(0.91-1.09)$ & $0.94(0.82-1.07)$ \\
\hline & Stomach & $1.27(0.84-1.91)$ & $1.18(0.68-2.05)$ \\
\hline & Pancreas & $0.80(0.60-1.06)$ & $1.10(0.68-1.78)$ \\
\hline & Brain & $0.93(0.59-1.47)$ & $0.83(0.43-1.60)$ \\
\hline & Lung & $1.01(0.84-1.22)$ & $0.79(0.64-0.99)^{*}$ \\
\hline & Renal & $1.16(0.81-1.68)$ & $1.30(0.68-2.48)$ \\
\hline & Lymphoma & $0.86(0.66-1.12)$ & $0.76(0.50-1.14)$ \\
\hline & Leukemias & $1.02(0.69-1.51)$ & $0.81(0.44-1.49)$ \\
\hline & Myeloma & $1.25(0.81-1.94)$ & $1.91(0.79-4.61)$ \\
\hline & Colorectal & $0.97(0.78-1.20)$ & $1.01(0.69-1.48)$ \\
\hline & Gynecological & $1.10(0.78-1.55)$ & $1.06(0.65-1.72)$ \\
\hline \multirow[t]{11}{*}{ Statins Vs. no treatment } & All cancers & $0.92(0.87-0.97)^{*}$ & $0.95(0.87-1.03)$ \\
\hline & Stomach & $0.81(0.64-1.03)$ & $0.98(0.72-1.34)$ \\
\hline & Pancreas & $1.01(0.84-1.22)$ & $0.91(0.69-1.19)$ \\
\hline & Brain & $0.97(0.73-1.27)$ & $1.11(0.74-1.66)$ \\
\hline & Lung & $0.93(0.83-1.06)$ & $0.94(0.81-1.10)$ \\
\hline & Renal & $0.97(0.77-1.21)$ & $0.91(0.63-1.32)$ \\
\hline & Lymphoma & $0.88(0.74-1.04)$ & $1.07(0.80-1.42)$ \\
\hline & Leukemias & $0.77(0.61-0.99)^{*}$ & $0.91(0.58-1.43)$ \\
\hline & Myeloma & $0.98(0.76-1.25)$ & $1.07(0.68-1.69)$ \\
\hline & Colorectal & $0.90(0.79-1.02)$ & $0.80(0.64-0.99)^{*}$ \\
\hline & Gynecological & $1.02(0.83-1.25)$ & $1.09(0.82-1.46)$ \\
\hline \multirow[t]{11}{*}{ Non-Statins Vs. no treatment } & All cancers & $0.92(0.84-1.01)$ & $1.01(0.88-1.16)$ \\
\hline & Stomach & $0.68(0.45-1.03)$ & $0.65(0.37-1.13)$ \\
\hline & Pancreas & $1.33(1.00-1.77)^{*}$ & $1.24(0.75-2.03)$ \\
\hline & Brain & $0.81(0.47-1.40)$ & $0.97(0.48-1.95)$ \\
\hline & Lung & $1.01(0.83-1.23)$ & $1.13(0.90-1.43)$ \\
\hline & Renal & $0.81(0.56-1.18)$ & $0.96(0.52-1.76)$ \\
\hline & Lymphoma & $0.97(0.74-1.27)$ & $1.42(0.92-2.18)$ \\
\hline & Leukemias & $0.81(0.55-1.19)$ & $0.99(0.55-1.78)$ \\
\hline & Myeloma & $0.80(0.52-1.23)$ & $0.69(0.26-1.79)$ \\
\hline & Colorectal & $0.84(0.67-1.05)$ & $0.83(0.57-1.22)$ \\
\hline & Gynecological & $0.84(0.57-1.23)$ & $1.06(0.61-1.83)$ \\
\hline
\end{tabular}

Thromb Res. Author manuscript; available in PMC 2018 October 01. 


\section{Table 4}

Cause-specific hazard ratios of venous thromboembolism within the statin-treated group by individual products and natural or synthetic statins.

\begin{tabular}{lll}
\hline Deep vein thrombosis & Statin used & Hazard ratio (95\% Confidence interval) \\
& Synthetic & Reference \\
& Natural & $0.96(0.90-1.03)$ \\
& Simvastatin & Reference \\
& Lovastatin & $1.07(0.93-1.23)$ \\
& Pravastatin & $0.99(0.89-1.11)$ \\
& Rosuvastatin & $1.02(0.91-1.15)$ \\
& Atorvastatin & $1.06(0.98-1.15)$ \\
& Fluvastatin & $1.03(0.67-1.59)$ \\
& Pitavastatin & $1.10(0.50-2.41)$ \\
Pulmonary embolism & Synthetic & Reference \\
& Natural & $1.01(0.92-1.12)$ \\
& Simvastatin & Reference \\
& Lovastatin & $0.91(0.73-1.14)$ \\
& Pravastatin & $0.97(0.82-1.14)$ \\
& Rosuvastatin & $0.91(0.76-1.09)$ \\
& Atorvastatin & $0.99(0.88-1.11)$ \\
& Fluvastatin & $0.99(0.53-1.86)$ \\
Pitavastatin & $1.78(0.74-4.26)$ \\
\hline & &
\end{tabular}

Thromb Res. Author manuscript; available in PMC 2018 October 01. 


\section{Table 5}

Cause-specific hazard ratios of venous thromboembolism within pairwise comparisons of the treatment groups stratified by age.

\begin{tabular}{lllll}
\hline & & Statins vs. non-statins & Statin vs. non-users & Non-statins vs. non-users \\
\hline Age & Outcome & $\begin{array}{l}\text { Hazard ratio }(95 \% \text { Confidence } \\
\text { interval) }\end{array}$ & $\begin{array}{l}\text { Hazard ratio (95\% Confidence } \\
\text { interval) }\end{array}$ & Hazard ratio (95\% Confidence interval) \\
55 years & DVT & $0.95(0.71-1.29)$ & $1.07(0.87-1.31)$ & $1.25(0.98-1.59)$ \\
& PE & $0.69(0.44-1.07)$ & $0.98(0.71-1.36)$ & $1.17(0.85-1.71)$ \\
$65-74$ years & DVT & $0.93(0.81-1.06)$ & $0.93(0.86-1.02)$ & $1.03(0.89-1.18)$ \\
& PE & $0.90(0.75-1.08)$ & $0.93(0.82-1.05)$ & $1.04(0.85-1.27)$ \\
275 years & DVT & $1.15(0.98-1.34)$ & $0.87(0.80-0.96)$ & $0.82(0.70-0.97)$ \\
& PE & $1.09(0.87-1.36)$ & $0.92(0.80-1.05)$ & $0.93(0.73-1.18)$ \\
\hline
\end{tabular}

Abbreviations: deep vein thrombosis (DVT); pulmonary embolism (PE). 